\title{
əNear-Surface Current Mapping by Shipboard Marine X-Band Radar: A Validation
}

\author{
BJÖRN LUND AND BRIAN K. HAUS \\ Rosenstiel School of Marine and Atmospheric Science, University of Miami, Miami, Florida \\ JOCHEN HORSTMANN \\ Helmholtz-Zentrum Geesthacht, Geesthacht, Germany \\ HANS C. GRABER \\ Rosenstiel School of Marine and Atmospheric Science, University of Miami, Miami, Florida \\ RUBEN CARRASCO \\ Helmholtz-Zentrum Geesthacht, Geesthacht, Germany
}

\author{
Nathan J. M. Laxague, Guillaume Novelli, Cédric M. Guigand, and Tamay M. ÖzgöKmen \\ Rosenstiel School of Marine and Atmospheric Science, University of Miami, Miami, Florida
}

(Manuscript received 7 September 2017, in final form 19 January 2018)

\begin{abstract}
The Lagrangian Submesoscale Experiment (LASER) involved the deployment of $~ 1000$ biodegradable GPStracked Consortium for Advanced Research on Transport of Hydrocarbon in the Environment (CARTHE) drifters to measure submesoscale upper-ocean currents and their potential impact on oil spills. The experiment was conducted from January to February 2016 in the Gulf of Mexico (GoM) near the mouth of the Mississippi River, an area characterized by strong submesoscale currents. A Helmholtz-Zentrum Geesthacht (HZG) marine X-band radar (MR) on board the R/V F. G. Walton Smith was used to locate fronts and eddies by their sea surface roughness signatures. The MR data were further processed to yield near-surface current maps at $\sim 500$-m resolution up to a maximum range of $\sim 3 \mathrm{~km}$. This study employs the drifter measurements to perform the first comprehensive validation of MR near-surface current maps. For a total of $4130 \mathrm{MR}$-drifter pairs, the root-mean-square error for the current speed is $4 \mathrm{~cm} \mathrm{~s}^{-1}$ and that for the current direction is $12^{\circ}$. The MR samples currents at a greater effective depth than the CARTHE drifters ( $1-5 \mathrm{~m}$ vs $\sim 0.4 \mathrm{~m}$ ). The mean MR-drifter differences are consistent with a wave- and wind-driven vertical current profile that weakens with increasing depth and rotates clockwise from the wind direction (by $0.7 \%$ of the wind speed and $15^{\circ}$ ). The technique presented here has great potential in observational oceanography, as it allows research vessels to map the horizontal flow structure, complementing the vertical profiles measured by ADCP.
\end{abstract}

\section{Introduction}

This study focuses on shipboard marine $\mathrm{X}$-band radar (MR) measurements of submesoscale $(\sim 100 \mathrm{~m}-10 \mathrm{~km})$ currents in the upper ocean. The quasi-two-dimensional wind-driven mesoscale flow field $(10-100 \mathrm{~km})$ and fully three-dimensional small-scale motions $(<100 \mathrm{~m})$ have

๑ Denotes content that is immediately available upon publication as open access.

Corresponding author: Björn Lund, blund@rsmas.miami.edu been extensively studied: The former for its role in transporting heat, momentum, and potential energy by the means of eddies (Gent and McWilliams 1990; Chelton et al. 2011), and the latter as a dissipative sink for kinetic energy (Ferrari and Wunsch 2009). Submesoscale currents arise in the presence of strong currents or horizontal density gradients and therefore vary regionally and temporally. Generation mechanisms include frontogenesis, unforced instabilities, and forced

Publisher's Note: This article was revised on 18 July 2018 to include an addition to the Acknowledgments section that provides a link to the data set used in this work. 
motions (e.g., by cross-front winds). Submesoscale currents can have large vertical velocities $\left(\sim 100 \mathrm{~m} \mathrm{day}^{-1}\right)$ and hence play an important role in upper-ocean mixing (Thomas et al. 2008). They also provide a pathway of energy transfer from mesoscale to small-scale motions (Nikurashin et al. 2013). Submesoscale currents have been poorly studied in the past, in large part as a result of the difficulty of their measurement: they are too large for buoy observations, too small for satellite altimetry, and evolve too rapidly for ship surveys. Similarly, most numerical circulation models have horizontal grids that are too coarse to resolve submesoscales.

Scientific interest in submesoscale currents has been growing since the early 2000s, when high-resolution (on the order of $1 \mathrm{~km}$ ) model simulations and satellite imagery ( $100 \mathrm{~m}$ or better) became more widespread (McWilliams 2016). Past field efforts to observe submesoscale currents used shipboard ADCP surveys (Callies and Ferrari 2013), a technique that requires averaging over an evolving ocean. A campaign involving a pair of research vessels equipped with ADCPs can remove this constraint (Shcherbina et al. 2013) but such effort is costly and results remain limited in resolution. The coordinated release of a large array of water-following drifters is an optimal means of measuring a submesoscale velocity field (Poje et al. 2014), although care must be given to the array design and timing of deployment (LaCasce 2008), and biases may result from the drifters' tendency to accumulate in convergence zones (Ohlmann et al. 2017). Current maps derived from high-frequency (HF) radar measurements are also capable of resolving submesoscale currents, depending on transmit frequency and range resolution (Haus et al. 2000). The disadvantage of HF radar is that multiple stations are required to obtain near-surface current vectors and that measurements are limited to coastal zones.

Today MRs are frequently being used to retrieve surface wave frequency-direction spectra (Young et al. 1985; Nieto Borge et al. 1999), significant wave height (Carrasco et al. 2017), bathymetry (Bell 1999; Senet et al. 2008), and surface wind velocity (Dankert et al. 2005; Lund et al. 2012), among other applications (Horstmann et al. 2015). MR sea surface backscatter intensity images may include an ocean wave signal given wavelengths $>$ $15 \mathrm{~m}$ and wind speeds $>2-3 \mathrm{~m} \mathrm{~s}^{-1}$ (Skolnik 1981; Hatten et al. 1998). This wave signal can be analyzed to yield an estimate of the near-surface current (Young et al. 1985; Senet et al. 2001). Such analysis is more difficult with shipborne MR data, since the ship motion risks contaminating the near-surface current signal. However, good results can be obtained if a highly accurate heading sensor is used (e.g., based on multiantenna GPS measurements) and possible offsets in the radar image's orientation relative to the ship heading are accounted for (Lund et al. 2015a). By analyzing the wave signal as a function of wavenumber, the vertical current shear in the upper ocean (effective depths of $\sim 1-10 \mathrm{~m}$ ) can be determined (Lund et al. 2015b; Campana et al. 2016, 2017).

While the aforementioned studies produced a single near-surface current vector or vertical profile per analysis period, others have demonstrated MR near-surface current mapping capabilities (Gangeskar 2002; Senet et al. 2008; Bell et al. 2012; Serafino et al. 2012; Hessner et al. 2014; Friedman 2014; Ludeno et al. 2016). MR near-surface current maps typically have a resolution of $\sim 500 \mathrm{~m}$ out to a maximum range of $\sim 3 \mathrm{~km}$ (or more, depending on the radar system) and a temporal resolution on the order of minutes. Although this makes MRs well suited for studying submesoscale currents, they have received scarce attention from the oceanographic research community. We believe this is at least partially resulting from the difficulties MR scientists have had in validating their near-surface current maps.

Most of the existing MR current mapping studies lack spatial reference measurements. The studies by Bell et al. (2012) and Friedman (2014) are limited to comparisons against ADCP measurements made at a single point, while Senet et al. (2008) altogether lack a reference for their MR current maps. Another difficulty stems from the fact that ADCPs measure currents in an Eulerian framework (i.e., without Stokes drift), whereas MR currents include a Stokes drift component (Ardhuin et al. 2009; Lund et al. 2015b). ADCP measurements furthermore do not always extend to the same near-surface layer covered by the radar. Similar comparability issues apply to the study by Hessner et al. (2014), which uses results from a coarse hydrodynamic model, where a single grid cell covers the entire radar field of view (FOV), as reference for its MR currents. The reference data presented in Gangeskar (2002), being based on a tidal model and local Doppler radar measurements, are equally ill-suited for validating MR current maps. HF radar current measurements could serve as an appropriate reference, assuming they have matching spatial resolution and known accuracy. But thus far only Serafino et al. (2012) have compared MR and HF radar near-surface currents, and in a purely qualitative way, based on a sole example. Here, we use Consortium for Advanced Research on Transport of Hydrocarbon in the Environment (CARTHE) drifters (Novelli et al. 2017), which constitute an ideal reference sensor. They are highly accurate, they sample the ocean's upper $\sim 0.6 \mathrm{~m}$, and, being Lagrangian, they include Stokes drift. There is one previous study that uses drifter measurements to validate MR current maps, but it is based on only $1.5 \mathrm{~h}$ of MR data and $18 \mathrm{MR}$-drifter measurement pairs (Ludeno et al. 2016). 
The near-surface current maps used in this study were collected with an Helmholtz-Zentrum Geesthacht (HZG) MR that was installed on the R/V F. G. Walton Smith during the Lagrangian Submesoscale Experiment (LASER) near the mouth of the Mississippi River in early 2016. The study area is affected by the mesoscale eddy field associated with the Gulf of Mexico (GoM) loop current, the Mississippi River discharge, and wind stress (Walker et al. 2005; Ortiz-Suslow et al. 2015). It is characterized by strong horizontal density gradients that are responsible for especially active submesoscale currents (Poje et al. 2014).

The goal of this study is to perform a first comprehensive validation of MR-derived near-surface current maps. To this end, the MR currents are compared against measurements from $\sim 1000$ GPS-tracked CARTHE drifters that were deployed from the R/V F. G. Walton Smith and Offshore Supply Vessel (OSV) Masco VIII during LASER. A large number of MR-drifter data pairs ensures that a broad range of environmental and sampling conditions are covered and that the results are statistically significant. This is also the first study to demonstrate shipboard MR near-surface current mapping capabilities, which poses the extra challenge of ship motion correction but allows for the sampling of remote ocean areas. Several examples of MR-measured submesoscale ocean current features and divergence fields are presented in conjunction with the corresponding backscatter intensity images. Submesoscale current features leave telltale signatures in these images that may serve as secondary validation of the MR current maps.

\section{Data overview}

This study is based on MR and drifter measurements made in the GoM during the LASER experiment from 20 January to 12 February 2016. The experiment was conducted by CARTHE and sponsored by the Gulf of Mexico Research Initiative (GoMRI). Its goal was to investigate submesoscale currents in the upper ocean and how they affect the transport of pollutants, such as oil. The experiment was centered around the deployment of $\sim 1000$ CARTHE drifters from the R/V F. G. Walton Smith and the OSV Masco VIII in the De Soto Canyon. In addition, it included extensive remote sensing (Rascle et al. 2017) and modeling efforts. Figure 1 shows a bathymetric map of the study area with the cruise track of the R/V F. G. Walton Smith, which includes several port stops in Gulfport, Mississippi.

A Doppler MR developed at HZG, Germany, was mounted at $\sim 12.5 \mathrm{~m}$ MSL on a mast on top of the wheelhouse of the R/V F. G. Walton Smith. The HZG MR is based on a commercial marine $\mathrm{X}$-band $(9.4 \mathrm{GHz})$

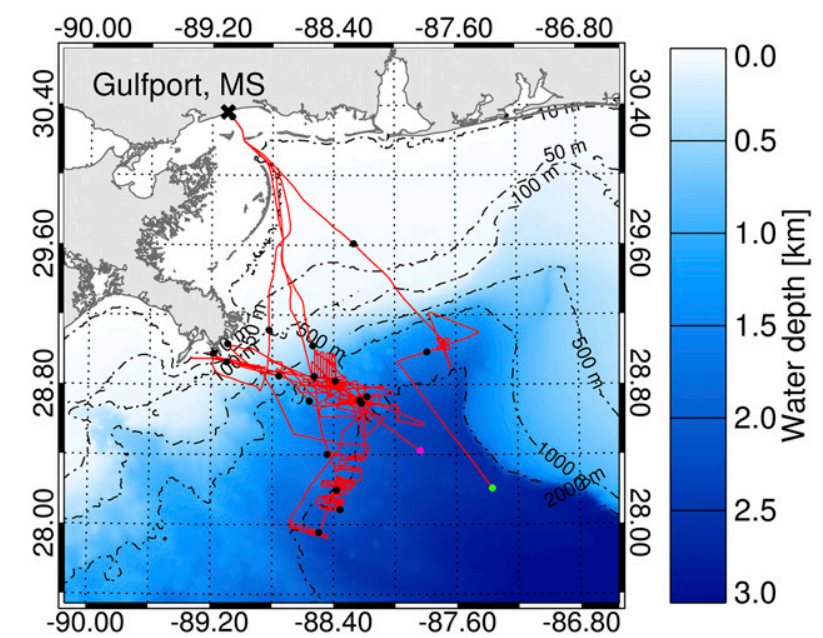

FIG. 1. Bathymetric map of the De Soto Canyon and track of the R/V F. G. Walton Smith (red lines) during the study period from $20 \mathrm{Jan}$ to $12 \mathrm{Feb} 2016$. The ship position after the passage of one day (black dots), the position at the beginning (green dots), and the position at the end of the study period (magenta dot). The bathymetric information stems from the General Bathymetric Chart of the Oceans (GEBCO) 2014 digital model (Weatherall et al. 2015).

radar with a 7.5-ft horizontal transmit and receive $(\mathrm{HH})$ polarized antenna, $12-\mathrm{kW}$ peak power output, and an antenna rotation period of $2 \mathrm{~s}$. It was modified to operate as a coherent-on-receive system, measuring both the phase and intensity of the radar backscatter (Braun et al. 2008). The MR has a pulse repetition frequency of $2 \mathrm{kHz}$ when operated with a 50-ns pulse length (short-pulse mode), which corresponds to a range resolution of $7.5 \mathrm{~m}$. The horizontal antenna beamwidth is $0.8^{\circ}$. The radar video signal (in the form of in-phase and quadrature components) is linearly amplified and sampled at $20 \mathrm{MHz}$, yielding a range pixel spacing that matches the radar's range resolution. Each pulse is sampled up to a maximum range of $\sim 3.1 \mathrm{~km}$ and with an image depth of 13 bit. Note that this study derives near-surface current maps from the radar backscatter intensity alone. It does not attempt to extract surface currents from the phase information, which shall be left to a future study. During the last leg of the experiment, the MR data have frequent gaps as a result of a malfunction in the acquisition server. Figure 2a shows the R/V F. G. Walton Smith and HZG MR at the dock of the University of Miami's Rosenstiel School of Marine and Atmospheric Science (RSMAS) in Miami, Florida.

The CARTHE drifters consist of two interlocking drogue panels, a flexible rubber tether, and a float with an integrated GPS transmitter and battery (see Fig. 2b). The drogue panels and floats are made of a biopolymer that is biodegradable. Each drogue panel is $0.38 \mathrm{~m} \times 0.38 \mathrm{~m}$, and 

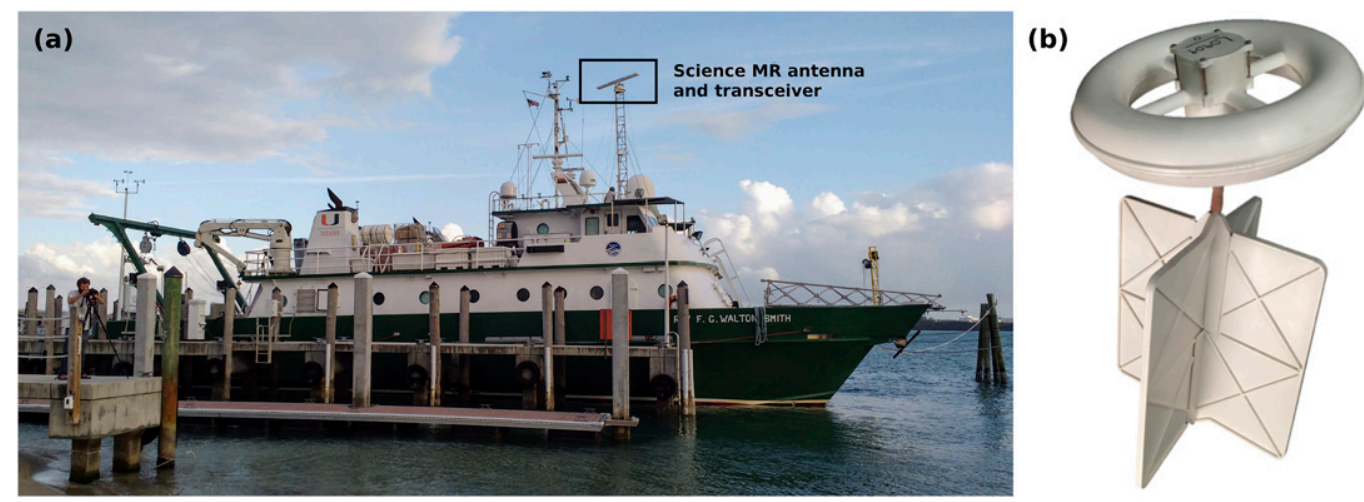

FIG. 2. (a) R/V F. G. Walton Smith at the RSMAS dock in Miami. The HZG MR (black frame) was mounted on a 5-m mast on top of the ship's wheelhouse during LASER. (b) Image of the CARTHE drifter.

the drogue is centered at a depth of $0.40 \mathrm{~m}$. The GPS transmitters are off-the-shelf, mass-produced units by Globalstar (SPOT Trace) that come with a low-cost yearly service subscription. They are powered by D-cell alkaline batteries, yielding an average of 60 days of GPS position fixes at 5 -min resolution with a position accuracy of $10 \mathrm{~m}$ or less.

The CARTHE drifters were calibrated in a windwave-current tank, where they have been shown to follow the average Lagrangian current (i.e., including wave-induced Stokes drift) of the ocean's upper $\sim 0.6 \mathrm{~m}$. The calibration measurements indicate that the CARTHE drifters have a wind slip velocity that is less than $0.5 \%$ of the equivalent $10-\mathrm{m}$ neutral wind speed $U_{10}$ (covering a range from 8 to $23 \mathrm{~m} \mathrm{~s}^{-1}$ ). For a $U_{10}$ of $8 \mathrm{~m} \mathrm{~s}^{-1}$, this implies an accuracy better than $\sim 0.04 \mathrm{~m} \mathrm{~s}^{-1}$. In field trials the CARTHE drifter velocities deviated by only $0.1 \%$ of $U_{10}$ from those of nearby Coastal Ocean Dynamics Experiment (CODE) drifters, which are drogued at 1-m depth (Davis 1985; Novelli et al. 2017).

During LASER most CARTHE drifters were deployed in large arrays in order to monitor the evolution of frontal convergence zones and submesoscale eddies. Two experiments on 21 January and 7 February involved the release of up to 300 drifters in dense multiscale arrays. Coordinated efforts involving both vessels allowed these deployments to be completed within only a few hours. Some of the drifters lost their drogue over the course of these deployments. The undrogued drifters suffered from elevated GPS dropout rates, as a result of flipped floaters, and exhibited an increased downwind drift. This study excludes measurements from undrogued drifters, which were identified using a rigorous quality control (Haza et al. 2018). After quality control, the drifter position fixes have a temporal resolution of $15 \mathrm{~min}$.
In addition to the MR and drifter data, this study uses measurements from an R. M. Young 05106 anemometer. It senses wind speed with a helicoid propeller with four blades and wind direction with a vane. The anemometer is mounted on the mast of the $\mathrm{R} / \mathrm{V} F$. $G$. Walton Smith at a height of $\sim 11 \mathrm{~m}$ MSL. Water depth measurements are obtained from the ship's Knudsen 3260 echo sounder. Highly accurate heading and position measurements are obtained from the ship's POS MV 320 inertial motion and dual-differential GPS sensor.

\section{Methodology}

The horizontally polarized grazing incidence MR sea surface backscatter is controlled by resonant Bragg scattering from centimeter-scale ripple waves (Brown 1998) and multipath scattering from small-scale breaking waves (Trizna 1997). Given a sufficiently rough sea surface, longer waves ( $>15 \mathrm{~m}$, i.e., twice the range resolution) appear in MR backscatter intensity images as alternating bands of enhanced and reduced backscatter. This can be explained by tilt and hydrodynamic modulation, that is, the longer waves' influence on the local incidence angle and roughness (Valenzuela 1978; Alpers et al. 1981; Plant and Keller 1990; Wetzel 1990). With increasing range, partial shadowing gains importance as a wave imaging mechanism (Nieto Borge et al. 2004; Plant and Farquharson 2012).

The near-surface current maps are derived from the wave signal within sequences of MR backscatter intensity images. The underlying method was developed by Young et al. (1985). It employs a three-dimensional (3D) FFT to convert an MR image sequence from space-time to wavenumber-frequency coordinates. The wave signal obeys the linear dispersion relationship 


$$
\omega= \pm \sqrt{g k \tanh k h}+\mathbf{k} \cdot \mathbf{U},
$$

where $\omega$ is the angular frequency, $k$ is the magnitude of the wavenumber vector $\mathbf{k}, h$ is the water depth, $g$ is the acceleration as a result of gravity, and $\mathbf{U}$ is the current vector. Within the 3D MR image spectrum, the wave signal is located on a surface that resembles an inverted cone, the so-called dispersion shell. Here, the dispersion shell is defined using $h$ from the echo sounder on the $\mathrm{R} / \mathrm{V}$ F. G. Walton Smith. Since the study area is in deep water with respect to waves (see Fig. 1), the errors that result from extending the shipborne depth measurements to the entire radar FOV are negligible. In the presence of a current, the Doppler effect manifests itself through translation and dilation of the dispersion shell in wavenumber-frequency space. The current is determined using a least squares fit that minimizes the wave signal's distance from the dispersion shell. It represents a weighted mean over the upper ocean, where the greatest weight is assigned to the surface (Stewart and Joy 1974; Ha 1979). The current's effective depth depends on the wavenumbers that are used in the current fit: the longer the waves, the greater the effective depth (Lund et al. 2015b; Campana et al. 2016, 2017).

The Young et al. (1985) method has since been improved by making the fit iterative and accounting for higher harmonics and aliasing (Senet et al. 2001). Other investigators have proposed alternative methods of measuring the wave signal's Doppler shift within the 3D MR image spectrum (Serafino et al. 2010; Shen et al. 2015). For current fit algorithms that are based on the Senet et al. (2001) method, the results' accuracy depends on the algorithm's ability to discriminate radar signal from noise. The wave signal experiences the largest Doppler shifts at high wavenumbers, where it generally approaches background noise level. Identifying the high-wavenumber signal is therefore key to achieving the best results (Lund et al. 2015b). Algorithms that are based on the normalized scalar product (NSP) method by Serafino et al. (2010) search for the current that maximizes the energy on the dispersion shell. They may be less prone to error, since they do not explicitly select wave spectral coordinates. But by maximizing the NSP, the method gives the greatest weight to the (generally more energetic) low-wavenumber components that are less sensitive to currents. Nevertheless, a recent intercomparison found that the retrieval methods by Senet et al. (2001), Serafino et al. (2010), and Shen et al. (2015) produce results of comparable accuracy (Huang et al. 2016).

The method employed here is based on Young et al. (1985) and Senet et al. (2001), but it includes several changes that 1) aim at an improved recognition of the

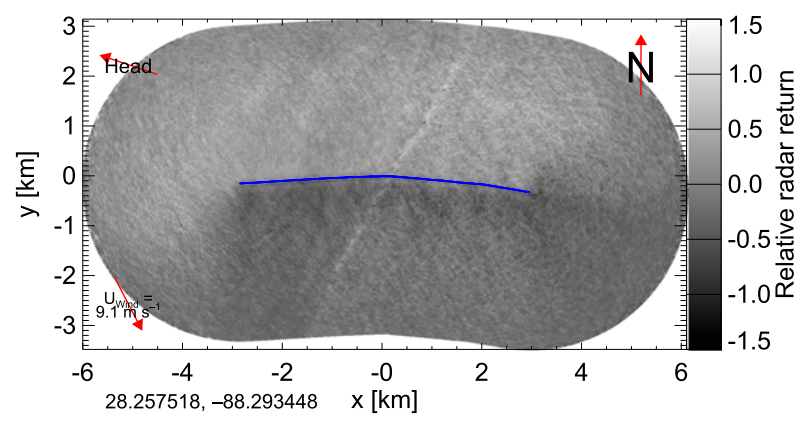

FIG. 3. Composite MR sea surface backscatter intensity image for 0945-1019 UTC 29 Jan 2016. Each image pixel corresponds to a 2-min average with near-range measurements being prioritized where available. The backscatter intensity has been logarithmically transformed. The grayscale ranges from black (low backscatter) to white (high backscatter). The corresponding track of the R/V F. G. Walton Smith is marked (blue). The red arrows in the corners indicate the geographic orientation, the mean ship heading, and the mean wind direction during the analysis period. The geographic location of the image origin (latitude and longitude, decimal degrees) is given at the bottom left.

high-wavenumber wave signal and 2) address shipmotion-related issues. Regarding point 1 , the $3 \mathrm{D}$ MR image spectra are divided by the background noise, which is determined empirically (with the assumption that it is a function of $k$ and $\omega$ only). The resulting signalto-noise ratio (SNR) spectra facilitate the identification of the high-wavenumber signal that might otherwise go undetected. The wave signal is identified in the polar coordinate space. At any given $\theta$ and $\omega$, only $k$ with the maximum SNR is attributed to the waves (skipping coordinates where SNR $<2$ ). This is to ensure that none of the selected $\theta$ and $\omega$ pairs have more than one $k$ assigned to them, which would go against the linear dispersion relationship (Lund et al. 2015b). As discussed by Senet et al. (2001), care must be taken to keep the fundamental mode, first harmonic, and aliased wave signal separate. Regarding point 2, the MR measurements are georeferenced on a pulse-by-pulse basis using true heading and position measurements from the POS MV 320. It is critical that a highly accurate (with an accuracy of $0.1^{\circ}$ or better) heading sensor is used, since even small heading errors may lead to large errors in the current measurements' cross-track component. For example, at a cruising speed of $5 \mathrm{~m} \mathrm{~s}^{-1}$, a $1^{\circ}$ compass error introduces a $0.09 \mathrm{~m} \mathrm{~s}^{-1}$ error in the cross-track current. Furthermore, care must be given to identify and remove offsets in the radar image orientation. Here, this is accomplished using the "calibration" method detailed in McCann and Bell (2018).

The analysis period used for this study is $\sim 30 \mathrm{~min}$; that is, it is based on 1024 consecutive radar images. Figure 3 gives an example of a composite HZG MR backscatter 


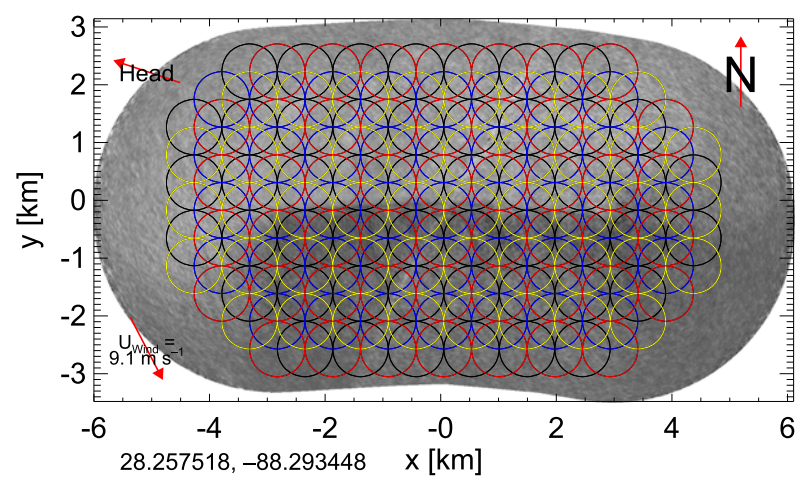

FIG. 4. MR near-surface current analysis windows for 09451019 UTC 29 Jan 2016. Each analysis window corresponds to an area of $\sim 0.7 \mathrm{~km}^{2}$ with neighboring ones overlapping by no more than $40 \%$. The analysis windows are plotted in different colors (red, yellow, blue, and black) to facilitate distinguishing between them. Analysis windows containing less than $\sim 8 \mathrm{~min}$ of MR measurements are disregarded.

intensity image covering one analysis period. Each image pixel corresponds to a 2-min average, where priority is given to near-range measurements. The MR backscatter intensity has been corrected for its range decay prior to averaging. In the figure the R/V F. G. Walton Smith is on a westward track. The pixels at the far right are based on the measurements from the analysis period's first $2 \mathrm{~min}$, those at the far left on the last $2 \mathrm{~min}$, and those in between are based on the $2 \mathrm{~min}$ of measurements around which the ship made its closest approach. The mean wind speed and direction during the analysis period were $9.1 \mathrm{~m} \mathrm{~s}^{-1}$ coming from $333^{\circ}$ (clockwise from north). The image shows a near-linear band of enhanced backscatter that the R/V F. G. Walton Smith crosses near the coordinate system's point of origin. This feature coincides with a front separating relatively fresh Mississippi River water on the east from oceanic water masses on the west. Based on the backsctter intensity image, the frontal width is $<100 \mathrm{~m}$.

Figure 4 shows the same image with the analysis windows overlayed. The windows are circular with a radius of $\sim 475 \mathrm{~m}$, covering an area of $\sim 0.7 \mathrm{~km}^{2}$ each. They are distributed uniformly over the radar FOV. The maximum overlap between neighboring analysis windows is $40 \%$. During an analysis period, the analysis windows remain geostationary, independent of ship motion.

Here, the MR backscatter intensity images are analyzed in blocks of 128 frames (i.e., $\sim 4 \mathrm{~min}$ ). Blocks are allowed to have a temporal overlap of $50 \%$. For each analysis window and $\sim 30$-min analysis period, all blocks of space-time data are converted to wavenumber-frequency space by 3D FFT. The resulting 3D spectra are averaged. To ensure that the spectra have the same frequency resolution, the blocks of MR images must first be interpolated such that they have a constant temporal resolution (which should match the average time difference between frames based on all blocks).

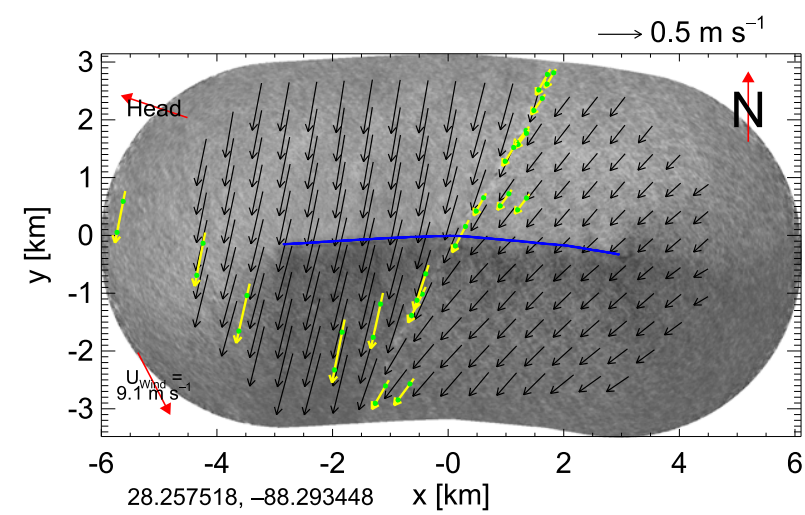

FIG. 5. MR near-surface current vectors (black) and corresponding drifter coordinates (green dots) and vectors (yellow) for 0945-1019 UTC 29 Jan 2016.

This is necessary because the antenna rotation period may vary slightly over time, and ship motion may further affect the blocks' temporal resolution. The number of blocks within each analysis window depends on the ship track. Here, results are reported only for analysis windows where a minimum of three blocks is available (which typically corresponds to $\sim 8 \mathrm{~min}$ of data). The results are subjected to a quality control that identifies outliers through comparison with neighboring measurements. The quality control reduced the total number of available MR nearsurface current vectors by $2.8 \%$, mostly affecting far-range measurements (where generally fewer blocks are available) under low-wind conditions.

Figure 5 gives the MR near-surface current map corresponding with Figs. 3 and 4. In addition to the MR vectors, the figure includes all coincident and collocated drifter vectors. The MR results reported in this study are based on the wave signal within the wavenumber range of $0.1-0.3 \mathrm{radm}^{-1}$, which implies an approximate effective depth of 2-5 m (assuming a linear profile) or 1-3 m (assuming an exponential profile) (Lund et al. 2015b). The MR nearsurface current map shows two current regimes that are separated by the frontal feature discussed above. The MR vectors on the Mississippi River (east) side of the front have an average speed of $0.29 \mathrm{~m} \mathrm{~s}^{-1}$ and a direction of $224^{\circ}$ (clockwise from north). The average vector on the oceanic (west) side has more than twice the speed at $0.62 \mathrm{~m} \mathrm{~s}^{-1}$ and a direction of $193^{\circ}$. The existence of two distinct current regimes is confirmed by the drifter vectors. However, the majority of the drifters appear to be trapped inside the frontal convergence zone, which will be analyzed further below.

\section{Results}

This section comprehensively validates the shipboard HZG MR near-surface current maps with coincident and 

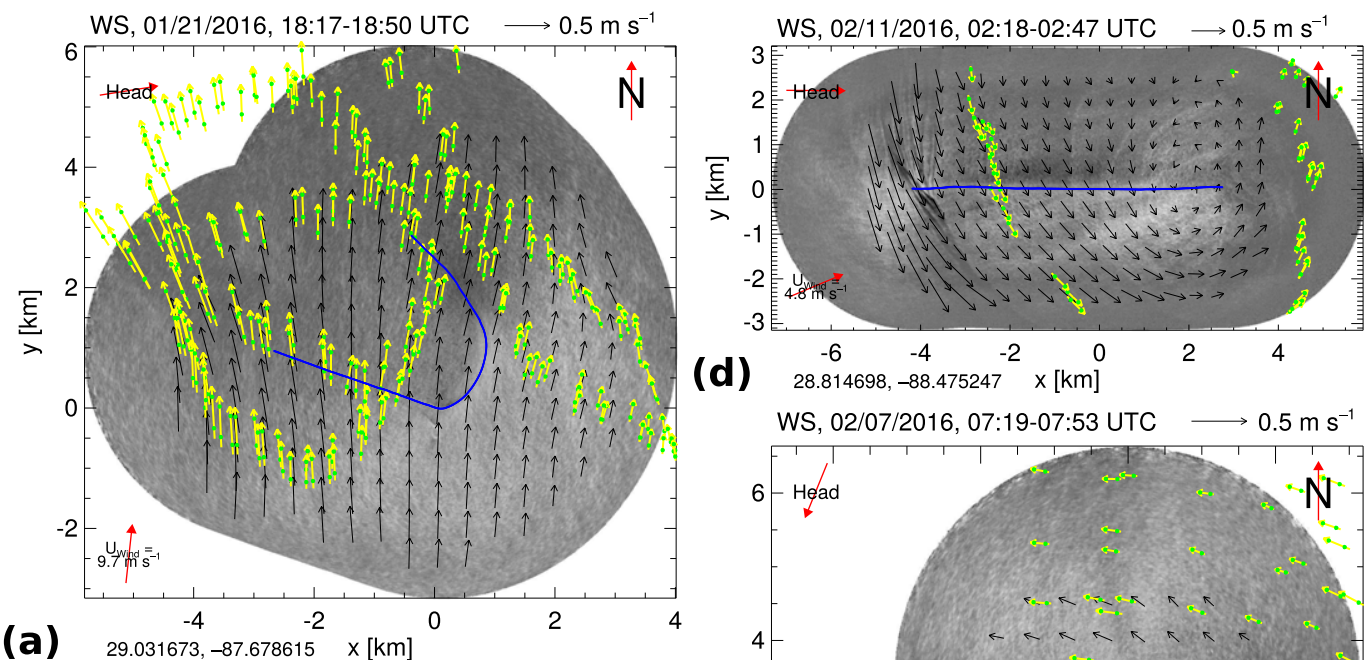

$29.031673,-87.678615 \quad x[\mathrm{~km}]$
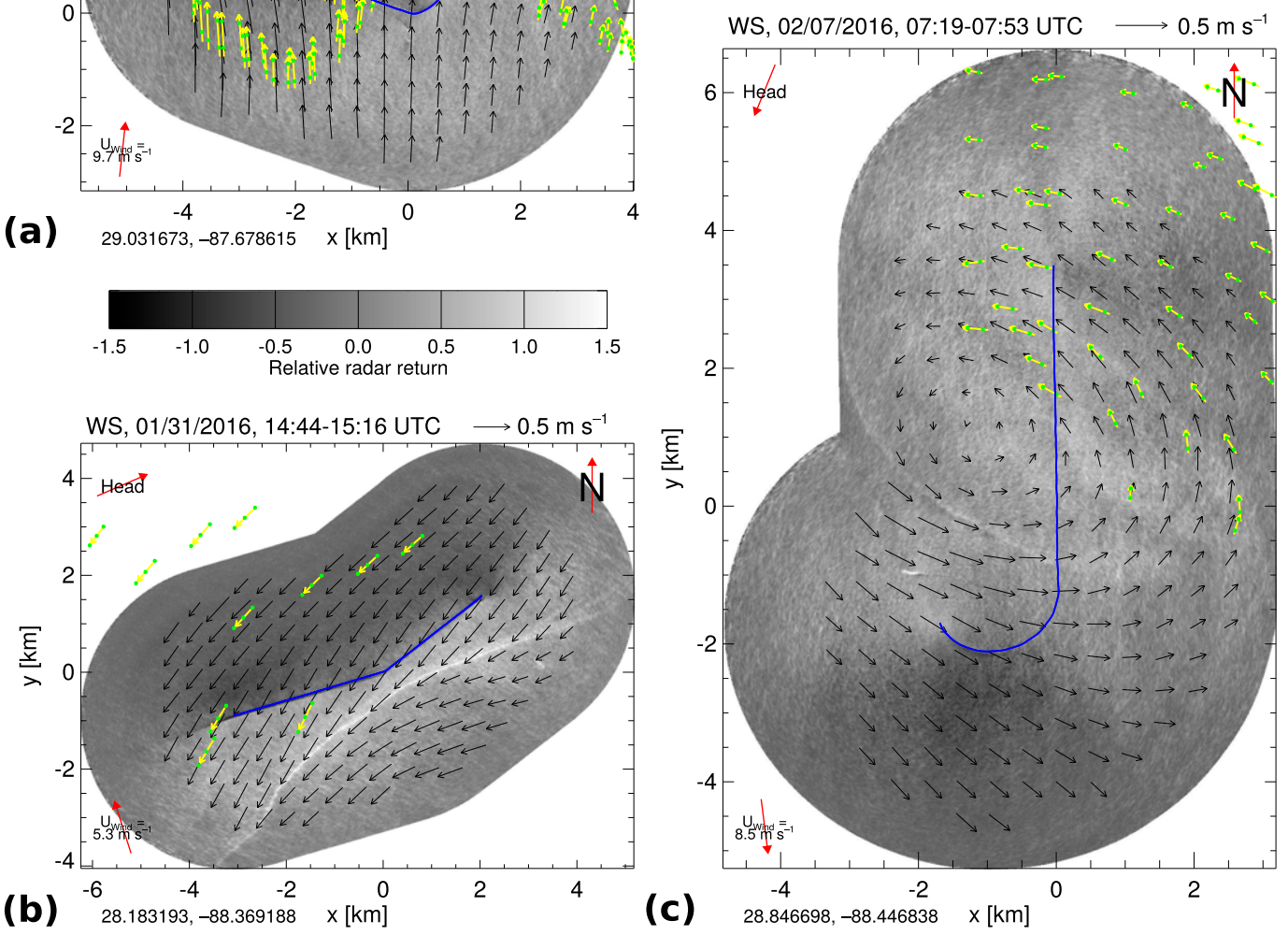

FIG. 6. Examples of MR near-surface current vectors (black) and corresponding drifter coordinates (green dots) and vectors (yellow) from (a) 1817-1850 UTC 21 Jan 2016, (b) 1444-1516 UTC 31 Jan 2016, (c) 0719-0753 UTC 7 Feb 2016, and (d) 0218-0247 UTC 11 Feb 2016. The backscatter intensity has been logarithmically transformed. The grayscale ranges from black (low backscatter) to white (high backscatter). The corresponding R/V $F$. $G$. Walton Smith cruise tracks are marked (blue lines).

collocated CARTHE drifter measurements. This is done using statistical comparison methods. To this end, each drifter vector is matched with an MR vector that has been bilinearly interpolated to the mean drifter position. The drifters measure two to three position fixes per $\sim 30$-min MR analysis period (after quality control). The drifter velocity is calculated from the distance and time between the first and last fix. The MR vectors are not extrapolated; that is, drifters whose mean position lies outside the area for which MR vectors are available are not considered.

We begin with a qualitative assessment of the MR results. Figure 6 shows a representative set of four MR near-surface current maps from 21 January, 31 January,
7 February, and 11 February 2016. Each panel includes the corresponding drifter vectors, the track of the R/V F. G. Walton Smith, and a composite MR backscatter intensity image. The MR and drifter vectors describe the same flow patterns in all panels. The MR-drifter agreement is good despite frequent ship heading changes, suggesting that the MR results are not compromised by ship motion.

Figure 6a gives an example of a relatively uniform downwind flow field. The mean wind during the MR analysis period came from $186^{\circ}$ at $9.7 \mathrm{~m} \mathrm{~s}^{-1}$. The panel includes 125 drifter vectors for which there is a matching MR vector. The measurements were acquired toward 
the end of the deployment of a massive drifter array in the form of a four-leaf clover. The array consisted of $\sim 215$ drifters and took $5 \mathrm{~h}$ to complete. The mean current speed and direction are $0.38 \mathrm{~m} \mathrm{~s}^{-1}$ and $3^{\circ}$ based on the drifters and $0.37 \mathrm{~m} \mathrm{~s}^{-1}$ and $2^{\circ}$ based on the MR, respectively. The MR and drifter speeds range from 0.20 to $0.57 \mathrm{~m} \mathrm{~s}^{-1}$ and from 0.25 to $0.58 \mathrm{~m} \mathrm{~s}^{-1}$, respectively. The MR and drifter directions range from $337^{\circ}$ to $16^{\circ}$ and from $337^{\circ}$ to $17^{\circ}$, respectively. The strongest currents are north-northwestward and occur in the upper-left quadrant of the panel. The weakest currents are north-northeastward in the lower-right quadrant.

Another example of a front separating Mississippi River waters (east) from oceanic waters (west) is shown in Fig. 6b. The mean winds were weaker than in the previous example, coming from $162^{\circ}$ at $5.3 \mathrm{~m} \mathrm{~s}^{-1}$. As in Fig. 5, the front is characterized by a band of enhanced backscatter that is $<100 \mathrm{~m}$ wide, but in this case it is curved. Drifter measurements are available on the oceanic side of the front, where they are in good agreement with the MR. For the six available MRdrifter pairs, the respective mean current speeds are 0.35 and $0.33 \mathrm{~m} \mathrm{~s}^{-1}$ and the mean directions are $219^{\circ}$ and $218^{\circ}$, respectively. The near-surface currents on the less saline side of the front are more variable and westward than the currents on the oceanic side.

Figure $6 c$ gives an example of an MR- and driftersensed submesoscale cyclonic eddy. The winds were southward (coming from $353^{\circ}$ ) at $8.5 \mathrm{~m} \mathrm{~s}^{-1}$. A curved band of enhanced backscatter in the panel's lower-left quadrant separates relatively strong southeastward currents from weaker ones near the eddy's core. The MR reveals an asymmetric eddy structure, with weaker currents in the eddy's lower-right and upper-left quadrants. The eddy has an approximate diameter of $5 \mathrm{~km}$ and maximum azimuthal speeds of $\sim 0.3 \mathrm{~m} \mathrm{~s}^{-1}$. The drifter vectors, available for the upper-right quadrant only, are consistent with the MR currents.

Last, Fig. 6d shows a highly variable near-surface current field that includes a sharp current front on the western end and another submesoscale cyclonic eddy on the eastern end. At the time of measurement, a wind of $4.8 \mathrm{~m} \mathrm{~s}^{-1}$ was coming from $247^{\circ}$. The MR current speeds in the example are ranging from 0.02 to $0.69 \mathrm{~m} \mathrm{~s}^{-1}$. The eddy has a similar diameter and strength as the one from the previous example. One narrowbanded structure of drifters moves southeastward. The corresponding current vectors are in good agreement with the MR results. Another cluster of drifters, located on the opposite half of the eddy, moves northeastward. Direct MR-drifter matches are lacking for this cluster, but the extrapolated MR observations concur with the drifter currents.

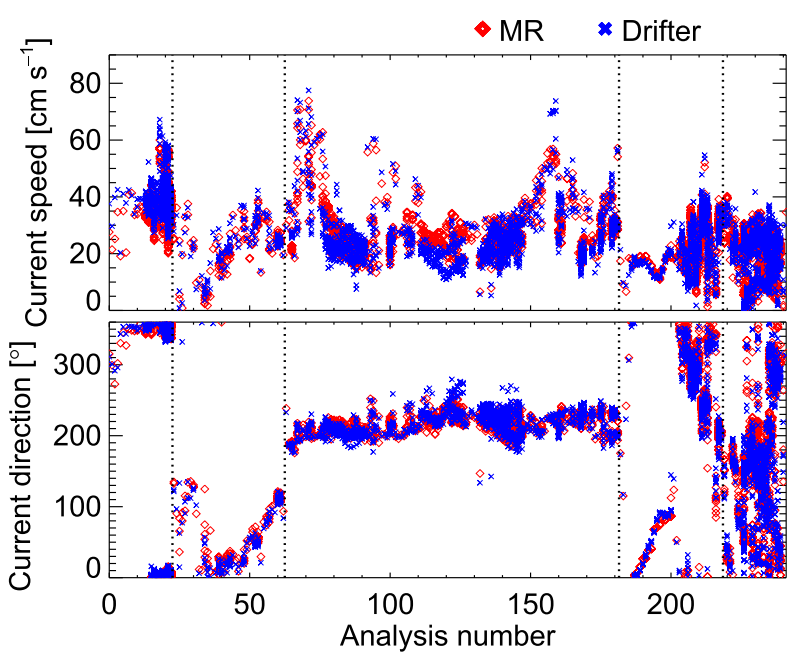

FIG. 7. Time series of collocated MR (red diamonds) and drifter (blue crosses) current speed and direction measurements. The time series includes 242 analysis periods of $\sim 30 \mathrm{~min}$ with a total of $4130 \mathrm{MR}$-drifter pairs. The first analysis number corresponds to 1556 UTC 20 Jan 2016 and the last one to 1914 UTC 12 Feb 2016. The temporal gaps in the time series are marked (vertical bars).

To quantify the agreement between the MR and drifter near-surface current measurements, we consider all periods during which there were drifters inside the radar FOV. Figure 7 shows a time series of near-surface current speed and direction that includes all available MR-drifter pairs. The number of MR-drifter pairs per analysis period ranges from 1 (on 54 occasions) to 125 (on a sole occasion; see Fig. 6a). In total, there are 4130 MR-drifter pairs during 242 analysis periods corresponding to $\sim 5.8$ days of MR measurements (analysis periods with data gaps are longer than the typical $\sim 30 \mathrm{~min})$. The first MR-drifter match occurred at 1556 UTC 20 January 2016 and the last match at 1914 UTC 12 February 2016. The time series indicates good MR-drifter agreement throughout the study period. The observed near-surface currents range from near zero to $0.74 \mathrm{~m} \mathrm{~s}^{-1}$ for the MR and $0.77 \mathrm{~m} \mathrm{~s}^{-1}$ for the drifters, covering virtually all directions. The corresponding winds were coming predominantly from the south with an overall mean speed of $6.8 \mathrm{~m} \mathrm{~s}^{-1}$ and 30 -min means ranging from 2.4 to $11.8 \mathrm{~m} \mathrm{~s}^{-1}$.

Figure 8 shows scatterplots of the $u$ (west-east) and $v$ (south-north) components of the MR and drifter currents (same data as in the previous figure). For $4130 \mathrm{MR}$-drifter data pairs, the coefficient of determination $r^{2}$ is 0.94 and 0.97 , the bias is -0.5 and $-0.5 \mathrm{~cm} \mathrm{~s}^{-1}$, the standard deviation of differences $\sigma_{x y}$ is 3.5 and $3.9 \mathrm{~cm} \mathrm{~s}^{-1}$, and the root-mean-square (RMS) error is 3.5 and $4.0 \mathrm{~cm} \mathrm{~s}^{-1}$, respectively. The same data expressed in terms of speed and direction have RMS errors of $4.0 \mathrm{~cm} \mathrm{~s}^{-1}$ and $12.2^{\circ}$, respectively. 

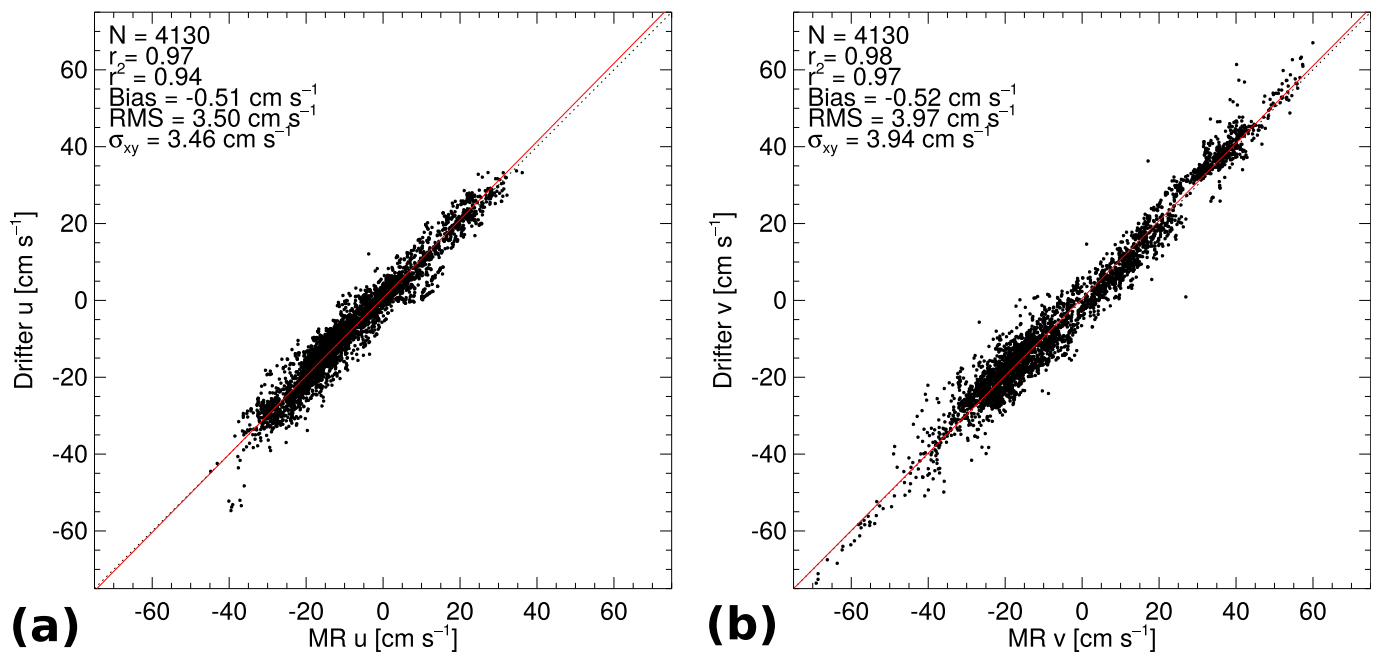

FIG. 8. Scatterplots of (a) $u$ and (b) $v$ components of the MR and drifter currents. Comparison statistics are given in the upper-left corner of each panel, and the best-fit line is shown (red).

The relative RMS differences with respect to the drifters' RMS velocity are $15 \%$ for the current speed, $21 \%$ for $u$, and $18 \%$ for $v$. The comparison statistics are summarized in Table 1. Assuming that the MR and drifters have equal and uncorrelated measurement errors, both sensors' accuracy (based on the RMS error) is $2.8 \mathrm{~cm} \mathrm{~s}^{-1}$ in terms of current speed, $2.5 \mathrm{~cm} \mathrm{~s}^{-1}$ in terms of $u$, and $2.8 \mathrm{~cm} \mathrm{~s}^{-1}$ in terms of $v$.

\section{Discussion}

Possible measurement errors aside, there are a number of reasons why MR and reference currents may differ. Given a vertically sheared flow, measurement differences will arise if the MR and the reference sensor sample the water column at different effective depths. Unlike MR, the reference sensor may not capture the Stokes drift. Last, they may reflect environmental variability (e.g., when comparing spatial vs point measurements). In the following, these issues will be addressed in greater detail.

The comparison of HZG MR and CARTHE drifter currents presented in the previous section yielded RMS errors that are significantly lower than what has previously been published. Lund et al. (2015a) report current speed and direction RMS errors of $10 \mathrm{~cm} \mathrm{~s}^{-1}$ and $30^{\circ}$, respectively, for their comparison of shipboard MR and ADCP measurements in the western Pacific. In their study, the topmost ADCP bin corresponds to a depth of $21 \mathrm{~m}$, whereas the MR currents are based on waves of $0.225 \mathrm{rad} \mathrm{m}^{-1}$, which corresponds to $2.2 \mathrm{~m}$ for a linear profile or $1.2 \mathrm{~m}$ for an exponential profile (Stewart and Joy 1974; Ha 1979). The different sampling depths are likely to blame for a significant share of their errors. Huang et al. (2016) compare near-surface current measurements from an MR installed on a research platform in the German Bight against those from a bottommounted ADCP (located in the radar FOV). They obtain the best MR-ADCP agreement by considering the ADCP's 6-m bin, with RMS errors from 7.2 to $8.4 \mathrm{~cm} \mathrm{~s}^{-1}$ for $u$ and $v$, but note that shallower ADCP measurements are likely corrupted as a result of the strong acoustic echo from the wavy surface. Part of the errors in their study can still be explained by differences in the MR and ADCP sampling depths.

Additional errors in Lund et al. (2015a) and Huang et al. (2016) stem from the fact that ADCPs yield Eulerian current measurements (i.e., without Stokes drift), while radar-derived currents include a Lagrangian component (Ardhuin et al. 2009). The surface Stokes

TABLE 1. Comparison statistics for all MR-drifter current velocity pairs $(N=4130)$. The term $R$ is a correlation coefficient for directional data. It is defined as the length of the vector mean of the set of unit vectors whose directions are set to the angle differences between the two series; 1 indicates perfect correlation. $\sigma_{x y}$ is the standard deviation.

\begin{tabular}{lcccc}
\hline \hline & $u$ & $v$ & Speed & Direction \\
\hline$r$ & 0.97 & 0.98 & 0.92 & - \\
$r^{2}$ & 0.94 & 0.97 & 0.85 & - \\
$R$ & - & - & - & 0.98 \\
Bias $\left(\mathrm{cm} \mathrm{s}^{-1}\right)$ or $\left(^{\circ}\right)$ & -0.51 & -0.52 & 0.32 & 1.32 \\
RMS $\left(\mathrm{cm} \mathrm{s}^{-1}\right)$ or $\left(^{\circ}\right)$ & 3.50 & 3.97 & 3.99 & 12.20 \\
$\sigma_{x y}\left(\mathrm{~cm} \mathrm{~s}^{-1}\right)$ or $\left(^{\circ}\right)$ & 3.46 & 3.94 & 3.98 & 12.13 \\
Relative RMS $(\%)$ & 21.3 & 18.0 & 14.5 & -
\end{tabular}


drift is of the same order of magnitude as the Ekman drift, with mean values of $8-10 \mathrm{~cm} \mathrm{~s}^{-1}$ in the Baltic Sea (Tuomi et al. 2018) and 2-10 $\mathrm{cm} \mathrm{s}^{-1}$ in the Pacific Ocean (Tamura et al. 2012). Since the CARTHE drifters measure currents in a Lagrangian frame of reference, they provide a better reference for our MR current mapping validation than a Eulerian sensor would (e.g., shipboard ADCP).

In a recent field study featuring measurements of the Lagrangian current profile to within $1 \mathrm{~cm}$ of the surface, Laxague et al. (2018) observed profound shear in the upper $2 \mathrm{~m}$ of the GoM water column. Hence, the question remains whether some of the observed MR-drifter differences are due to the different sampling depths ( $1-5 \mathrm{~m}$ for the MR vs $\sim 0.4 \mathrm{~m}$ for the drifters). To shed light on this question, we repeat our statistical comparison with the along- and across-wind components of the MR and drifter currents (which were determined using the wind direction from the shipboard anemometer). Compared with the MR, which senses the currents at a greater effective depth, the drifters' alongwind currents are biased high by $1.6 \mathrm{~cm} \mathrm{~s}^{-1}$ with a $\sigma_{x y}$ of $3.4 \mathrm{~cm} \mathrm{~s}^{-1}$. The drifters' across-wind currents are biased low by $0.5 \mathrm{~cm} \mathrm{~s}^{-1}$ with a $\sigma_{x y}$ of $3.7 \mathrm{~cm} \mathrm{~s}^{-1}$. The mean difference speed is $0.7 \%$ of the wind speed and the mean difference direction is $15^{\circ}$. These biases are significant and consistent with a wave- and wind-driven profile that weakens with increasing depth and rotates clockwise (Lewis and Belcher 2004). Thus, some of the RMS errors in the MR-drifter comparison can indeed be explained by the sensors' different sampling depths and upper-ocean vertical shear.

The differences between MR and reference measurements that are due to environmental variability are more difficult to quantify. Here, MR-drifter differences arise from the fact that the MR currents represent spatial averages over $\sim 0.7 \mathrm{~km}^{2}$, whereas the drifters measure currents along their respective paths only. At times when there is large small-scale $(<500 \mathrm{~m})$ variability, which the MR is unable to resolve, these differences are likely exacerbated.

For example, Fig. 9 shows two contour plots of MRbased divergence normalized by the local inertial frequency (or Coriolis frequency) with the corresponding composite backscatter intensity images. Divergence $\gamma$ is defined as

$$
\gamma=\frac{1}{2}\left(u_{x}+v_{y}\right)
$$

where $u_{x}$ and $v_{y}$ are spatial current gradients. Figures 5 and $6 \mathrm{~b}$ show the corresponding near-surface current maps (note that, prior to computing divergence, the

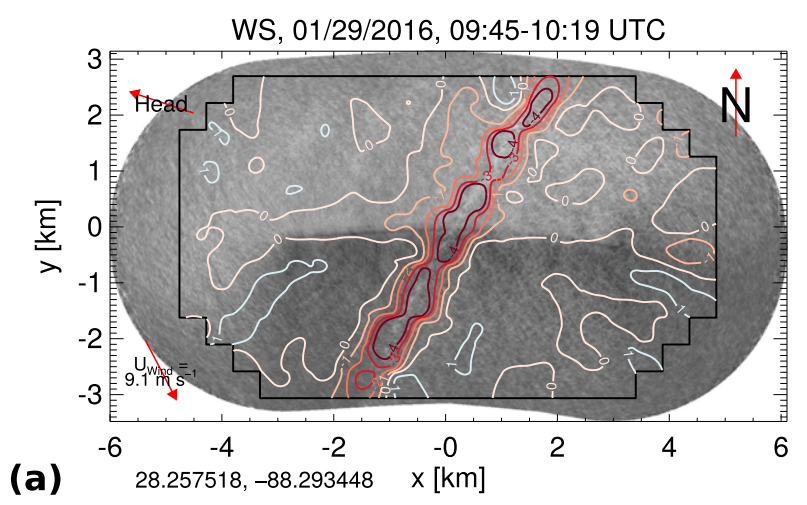

(a)

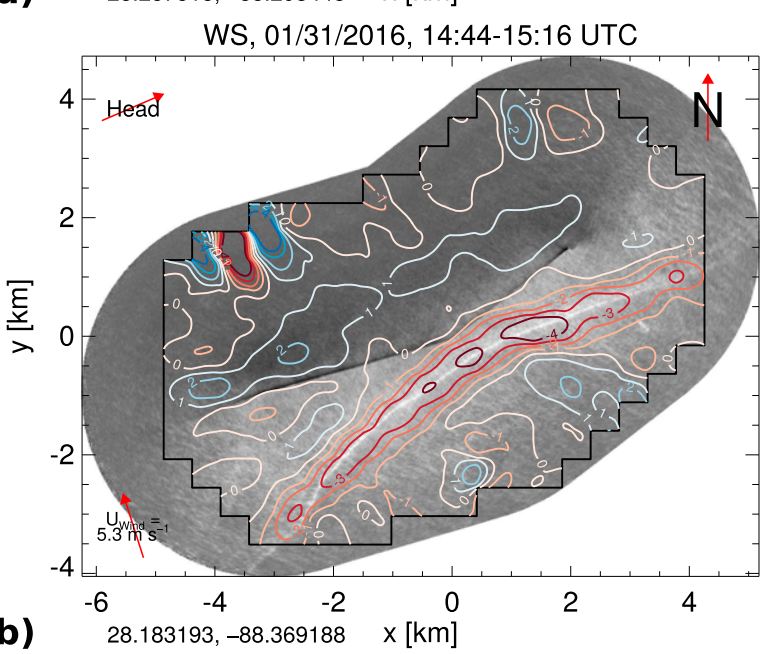

(b)

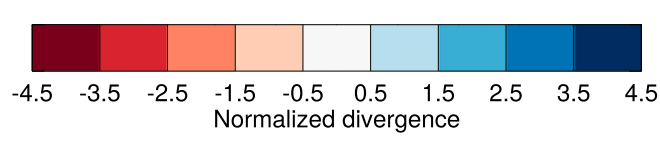

FIG. 9. MR-derived divergence normalized by the inertial frequency and corresponding composite sea surface backscatter intensity image for (a) 0945-1019 UTC 29 Jan 2016 and (b) 1444 1516 UTC 31 Jan 2016. The color scale ranges from dark red (strongly convergent flow) to dark blue (strongly divergent flow). The areas (black frames) for which near-surface current vectors are available.

velocity maps were interpolated to $7.5-\mathrm{m}$ resolution using a minimum curvature surface fitting method). Both plots show a strongly convergent flow (with normalized divergence minima $<-4$ ) coinciding perfectly with the frontal features characterized by enhanced radar backscatter. This is in accordance with the radar imaging theory of hydrodynamic modulation. The converging currents enhance the surface roughness that is responsible for the radar echo (Alpers et al. 1981). Drifters have a tendency to accumulate in convergent regions (Ohlmann et al. 2017), as Figs. 5 and 9a confirm. Based on the MR backscatter intensity images, the ocean fronts observed during this study were typically $<100 \mathrm{~m}$ wide. The MR currents that are paired with drifter measurements from frontal 
convergence zones are therefore likely representative of a different flow regime, explaining a portion of the observed MR-drifter differences.

Another question to explore is whether the MRdrifter agreement differs from near to far range. MRs are best able to image short waves in the near range, which can be explained by the incident microwave energy's cubic decay with range and the deteriorating azimuth resolution with range (Gommenginger et al. 2000; Dankert et al. 2005; Lund et al. 2014). (The crossrange resolution reaches parity with the along-range resolution at a range of $\sim 540 \mathrm{~m}$, at a range of $3 \mathrm{~km}$ it is $\sim 42 \mathrm{~m}$.) Since short waves experience larger currentinduced Doppler shifts than long waves, the current fit may be more accurate in the near range. To test this, the MR-drifter pairs are sorted by their closest approach to the R/V F. G. Walton Smith during their respective analysis periods. They are then split into two equal halves at the closest approach distance of $1078 \mathrm{~m}$. The abovementioned statistical comparison is repeated for each half. The near- and far-range RMS errors for $u$ are both $3.5 \mathrm{~cm} \mathrm{~s}^{-1}$ and for $v$ they are 3.8 and $4.0 \mathrm{~cm} \mathrm{~s}^{-1}$, respectively. Hence, within the given maximum range of $\sim 3 \mathrm{~km}$, the MR near-surface current maps' accuracy can be considered range independent.

\section{Conclusions}

This study is the first comprehensive validation of MR-derived near-surface current maps. The measurements were made using an HZG MR that was installed on the R/V F. G. Walton Smith during a cruise in the GoM in early 2016. The cruise was part of the GoMRIfunded LASER experiment, which was centered around the deployment of $\sim 1000$ GPS-tracked CARTHE drifters (Novelli et al. 2017). To our knowledge no shipboard MR near-surface current maps have previously been published in the scientific literature. The drifters are an excellent reference sensor. Like the MR currents, which include a Lagrangian component (Ardhuin et al. 2009), they measure the current in a Lagrangian reference frame. What is probably more important is that both MR and drifters yield currents that correspond to the ocean's near-surface layer (1-5 m for the MR and $\sim 0.4 \mathrm{~m}$ for the drifters). The MR-drifter current comparison presented here is of an unprecedented size and scope. A total of 4130 data pairs (from $240 \mathrm{MR}$ analysis periods corresponding to $\sim 5.8$ days of measurements) are available, covering winds from 2 to $12 \mathrm{~m} \mathrm{~s}^{-1}$. The comparison statistics indicate a measurement accuracy that is significantly better than any previously reported results, with RMS errors of $3.5 \mathrm{~cm} \mathrm{~s}^{-1}$ for $u$ and $4.0 \mathrm{~cm} \mathrm{~s}^{-1}$ for $v$.
Several reasons explaining some of the remaining MR-drifter differences were discussed. The different sampling depths result in the MR observing slightly weaker currents that are deflected clockwise, as can be explained by Ekman veering. On average the MRdrifter difference vectors have a magnitude that is $0.7 \%$ of the wind speed and a $15^{\circ}$ deflection angle relative to the wind direction. The drifters' tendency to accumulate in convergence regions is likely responsible for additional errors. Considering these systematic differences and issues, and assuming equal and uncorrelated measurement errors, the MR provides a current speed accuracy that is likely better than the observed $2.8 \mathrm{~cm} \mathrm{~s}^{-1}$. The MR near-surface currents' accuracy was furthermore shown to be range independent.

Two examples were presented that show MR-based maps of upper-ocean divergence. These maps revealed regions of convergent flow (with normalized divergences of $<-4)$ that coincide perfectly with narrow $(<100 \mathrm{~m})$ bands of enhanced MR backscatter intensity. Similarly, the MR near-surface current maps can be used to compute vorticity. For example, near the cores of the submesoscale cyclonic eddies in Figs. $6 \mathrm{c}$ and $6 \mathrm{~d}$, the normalized vorticity $\eta=1 / 2\left(v_{x}-u_{y}\right)$, with $v_{x}$ and $u_{y}$ being spatial current gradients, reached minima of $<-5$ (not shown).

Several improvements were made to the MR current retrieval methodology. They concern the ship motion correction, which is a crucial step for shipboard current measurements (Lund et al. 2015a), and the wave signal discrimination from the background noise (Lund et al. 2015b). It has been shown that MRs are capable of measuring near-surface vertical current shear (Lund et al. 2015b; Campana et al. 2016, 2017). We are presently working on extending our MR near-surface current mapping technique to include vertical current shear measurements. Our future goal is to use the MR Doppler velocities (based on the system's complex signal) to determine surface current velocities (Braun et al. 2008). To complement the MR observations, we are furthermore developing a technique that uses optical video from a quadcopter to retrieve current fields at much higher (on the order of meters) spatial resolution (Dugan et al. 2001; Streßer et al. 2017).

Shipboard MR near-surface current maps and composite backscatter images, as well as surface wave frequency-direction spectra (Lund et al. 2016, 2017; Carrasco et al. 2017), can be produced in near-real time using a state-of-the-art laptop computer. Routinely available MR near-surface current maps and surface wave spectra could prove invaluable during search and rescue operations (e.g., when responding to man overboard situations), for oil spill mitigation efforts, or to enhance marine safety (e.g., when navigating narrow channels). The best results can be expected if the MR 
antenna is given a prominent position (i.e., as high as possible and with as little shadowing by ship super structures as possible), if the transceiver has a high peak power output (e.g., $25 \mathrm{~kW}$ ), if the antenna has a minimum length of $8 \mathrm{ft}$ and is vertically polarized (Huang and Gill 2012), and if a highly accurate analog-to-digital converter is used, capable of acquiring all pulses (typically, radars operating in short-pulse mode have a pulse repetition frequency of 2$3 \mathrm{kHz}$ ) with at least 12-bit image depth, at an appropriate resolution, and up to a maximum range of 4-6 km.

We hope this study will motivate seagoing oceanographers to put MRs to more routine use. MRs can map the horizontal flow structure around a research vessel, complementing the vertical profiles obtained by ADCPs, which are commonplace today. They are capable of continuously monitoring a remote area's upperocean flow, whereas drifter arrays will deform and eventually leave the study area, and HF radars are limited to coastal zones. In the future MRs could be used operationally not only to detect submesoscale features but also to quantify their flow characteristics (e.g., the diameter, maximum azimuthal speed, and vorticity of an eddy), and study their spatiotemporal evolution.

Acknowledgments. BL and HCG acknowledge funding by the U.S. Office of Naval Research (Grants N00014-13-1-0288 and N00014-15-1-2638). JH and RC were funded by the German Federal Ministry for Economic Affairs and Energy through the Coastal Observing System for Northern and Arctic Seas (Awards 0327533C and 0325915C). The authors are grateful to Jan Bödewadt, Michael Rebozo, Sanchit Mehta, Ming Shao, Hanjing Dai, Denis Ilias, and Shawn Lake for their support in installing and operating the MR. The LASER experiment was made possible by a grant from the Gulf of Mexico Research Initiative. The radar-based near-surface current data are publicly available through the Gulf of Mexico Research Initiative Information \& Data Cooperative (GRIIDC) at https://data.gulfresearchinitiative. org (doi: 10.7266/N7N01550).

\section{REFERENCES}

Alpers, W. R., D. B. Ross, and C. L. Rufenach, 1981: On the detectability of ocean surface waves by real and synthetic aperture radar. J. Geophys. Res., 86, 6481-6498, https://doi.org/ 10.1029/JC086iC07p06481.

Ardhuin, F., L. Marié, N. Rascle, P. Forget, and A. Roland, 2009: Observation and estimation of Lagrangian, Stokes, and Eulerian currents induced by wind and waves at the sea surface. J. Phys. Oceanogr., 39, 2820-2838, https://doi.org/10.1175/ 2009JPO4169.1.

Bell, P. S., 1999: Shallow water bathymetry derived from an analysis of X-band marine radar images of waves. Coastal Eng., 37, 513-527, https://doi.org/10.1016/S0378-3839(99)00041-1.
_ J. Lawrence, and J. V. Norris, 2012: Determining currents from marine radar data in an extreme current environment at a tidal energy test site. 2012 IEEE International Geoscience and Remote Sensing Symposium, IEEE, 7647-7650, https:// doi.org/10.1109/IGARSS.2012.6351856.

Braun, N., F. Ziemer, A. Bezuglov, M. Cysewski, and G. Schymura, 2008: Sea-surface current features observed by Doppler radar. IEEE Trans. Geosci. Remote Sens., 46, 1125-1133, https:// doi.org/10.1109/TGRS.2007.910221.

Brown, G. S., 1998: Guest editorial. IEEE Trans. Antennas Propag., 46, 1-2, https://doi.org/10.1109/TAP.1998.655445.

Callies, J., and R. Ferrari, 2013: Interpreting energy and tracer spectra of upper-ocean turbulence in the submesoscale range (1-200 km). J. Phys. Oceanogr., 43, 2456-2474, https://doi.org/ 10.1175/JPO-D-13-063.1.

Campana, J., E. J. Terrill, and T. de Paolo, 2016: The development of an inversion technique to extract vertical current profiles from X-band radar observations. J. Atmos. Oceanic Technol., 33, 2015-2028, https://doi.org/10.1175/JTECH-D-15-0145.1.

- — , and - 2017: A new inversion method to obtain upper-ocean current-depth profiles using X-band observations of deep-water waves. J. Atmos. Oceanic Technol., 34, 957-970, https://doi.org/10.1175/JTECH-D-16-0120.1.

Carrasco, R., J. Horstmann, and J. Seemann, 2017: Significant wave height measured by coherent X-band radar. IEEE Trans. Geosci. Remote Sens., 55, 5355-5365, https://doi.org/10.1109/ TGRS.2017.2706067.

Chelton, D. B., M. G. Schlax, and R. M. Samelson, 2011: Global observations of nonlinear mesoscale eddies. Prog. Oceanogr., 91, 167-216, https://doi.org/10.1016/j.pocean.2011.01.002.

Dankert, H., J. Horstmann, and W. Rosenthal, 2005: Wind- and wave-field measurements using marine X-band radar-image sequences. IEEE J. Oceanic Eng., 30, 534-542, https://doi.org/ 10.1109/JOE.2005.857524.

Davis, R. E., 1985: Drifter observations of coastal surface currents during CODE: The statistical and dynamical views. J. Geophys. Res., 90, 4756-4772, https://doi.org/10.1029/JC090iC03p04756.

Dugan, J. P., C. C. Piotrowski, and J. Z. Williams, 2001: Water depth and surface current retrievals from airborne optical measurements of surface gravity wave dispersion. J. Geophys. Res., 106, 16903-16915, https://doi.org/ 10.1029/2000JC000369.

Ferrari, R., and C. Wunsch, 2009: Ocean circulation kinetic energy: Reservoirs, sources, and sinks. Annu. Rev. Fluid Mech., 41, 253-282, https://doi.org/10.1146/annurev. fluid.40.111406.102139.

Friedman, J., 2014: Development of an X-band radar depth inversion model at the sand motor. M.S. thesis, Dept. of Hydraulic Engineering, Delft University of Technology, $81 \mathrm{pp}$.

Gangeskar, R., 2002: Ocean current estimated from X-band radar sea surface images. IEEE Trans. Geosci. Remote Sens., 40, 783-792, https://doi.org/10.1109/TGRS.2002.1006346.

Gent, P. R., and J. C. McWilliams, 1990: Isopycnal mixing in ocean circulation models. J. Phys. Oceanogr., 20, 150-155, https:// doi.org/10.1175/1520-0485(1990)020<0150:IMIOCM >2.0.CO;2.

Gommenginger, C. P., N. P. Ward, G. J. Fisher, I. S. Robinson, and S. R. Boxall, 2000: Quantitative microwave backscatter measurements from the ocean surface using digital marine radar images. J. Atmos. Oceanic Technol., 17, 665-678, https://doi.org/ 10.1175/1520-0426(2000)017<0665:QMBMFT>2.0.CO;2.

Ha, E.-C., 1979: Remote sensing of ocean surface current and current shear by HF backscatter radar. Stanford University Stanford Electronics Laboratory Tech. Rep., 141 pp. 
Hatten, H., J. Seemann, J. Horstmann, and F. Ziemer, 1998: Azimuthal dependence of the radar cross section and the spectral background noise of a nautical radar at grazing incidence. IGARSS '98: 1998 IEEE International Geoscience and Remote Sensing Symposium Proceedings, Vol. 5, IEEE, 2490-2492, https://doi.org/10.1109/IGARSS.1998.702255.

Haus, B. K., J. D. Wang, J. Rivera, J. Martinez-Pedraja, and N. Smith, 2000: Remote radar measurement of shelf currents off Key Largo, Florida, U.S.A. Estuarine Coastal Shelf Sci., 51, 553-569, https://doi.org/10.1006/ecss.2000.0704.

Haza, A. C., and Coauthors, 2018: Drogue-loss detection for surface drifters during the Lagrangian Submesoscale Experiment (LASER). J. Atmos. Oceanic Technol., 35, 705-725, https://doi.org/ 10.1175/JTECH-D-17-0143.1.

Hessner, K., K. Reichert, J. C. Nieto Borge, C. L. Stevens, and M. J. Smith, 2014: High-resolution X-band radar measurements of currents, bathymetry and sea state in highly inhomogeneous coastal areas. Ocean Dyn., 64, 989-998, https://doi.org/10.1007/s10236-014-0724-7.

Horstmann, J., J. C. Nieto Borge, J. Seemann, R. Carrasco, and B. Lund, 2015: Wind, wave, and current retrieval utilizing X-band marine radars. Coastal Ocean Observing Systems, Y. Liu, H. Kerkering, and R. H. Weisberg, Eds., Academic Press, 281-304, https://doi.org/10.1016/B978-0-12-802022-7.00016-X.

Huang, W., and E. Gill, 2012: Surface current measurement under low sea state using dual polarized X-band nautical radar. IEEE J. Sel. Topics Appl. Earth Obs. Remote Sens., 5, 18681873, https://doi.org/10.1109/JSTARS.2012.2208179.

_ - R. Carrasco, C. Shen, E. W. Gill, and J. Horstmann, 2016: Surface current measurements using $\mathrm{X}$-band marine radar with vertical polarization. IEEE Trans. Geosci. Remote Sens., 54, 2988-2997, https://doi.org/10.1109/TGRS.2015.2509781.

LaCasce, J. H., 2008: Statistics from Lagrangian observations. Prog. Oceanogr., 77, 1-29, https://doi.org/10.1016/j.pocean.2008.02.002.

Laxague, N. J. M.., and Coauthors, 2018: Observations of nearsurface current shear help describe oceanic oil and plastic transport. Geophys. Res. Lett., 45, 245-249, https://doi.org/ 10.1002/2017GL075891.

Lewis, D., and S. Belcher, 2004: Time-dependent, coupled, Ekman boundary layer solutions incorporating Stokes drift. Dyn. Atmos. Oceans, 37, 313-351, https://doi.org/ 10.1016/j.dynatmoce.2003.11.001.

Ludeno, G., C. Nasello, F. Raffa, G. Ciraolo, F. Soldovieri, and F. Serafino, 2016: A comparison between drifter and X-band wave radar for sea surface current estimation. Remote Sens., $\mathbf{8}$, 695, https://doi.org/10.3390/rs8090695.

Lund, B., H. C. Graber, and R. Romeiser, 2012: Wind retrieval from shipborne nautical $\mathrm{X}$-band radar data. IEEE Trans. Geosci. Remote Sens., 50, 3800-3811, https://doi.org/10.1109/ TGRS.2012.2186457.

- C. O. Collins III, H. C. Graber, E. Terrill, and T. H. C. Herbers, 2014: Marine radar ocean wave retrieval's dependency on range and azimuth. Ocean Dyn., 64, 999-1018, https://doi.org/10.1007/s10236-014-0725-6.

— , H. C. Graber, K. Hessner, and N. J. Williams, 2015a: On shipboard marine X-band radar near-surface current "calibration." J. Atmos. Oceanic Technol., 32, 1928-1944, https:// doi.org/10.1175/JTECH-D-14-00175.1.

,-- H. Tamura, C. O. Collins III, and S. M. Varlamov, 2015b: A new technique for the retrieval of near-surface vertical current shear from marine X-band radar images. J. Geophys. Res. Oceans, 120, 8466-8486, https://doi.org/ 10.1002/2015JC010961.
- C. O. I. Collins, H. Tamura, and H. C. Graber, 2016: Multidirectional wave spectra from marine X-band radar. Ocean Dyn., 66, 973-988, https://doi.org/10.1007/s10236-016-0961-z.

_ C. J. Zappa, H. C. Graber, and A. Cifuentes-Lorenzen, 2017: Shipboard wave measurements in the Southern Ocean. J. Atmos. Oceanic Technol., 34, 2113-2126, https://doi.org/ 10.1175/JTECH-D-16-0212.1.

McCann, D. L., and P. S. Bell, 2018: A simple offset "calibration" method for the accurate geographic registration of ship-borne X-band radar intensity imagery. IEEE Access, 6, 13 939-13 948, https://doi.org/10.1109/ACCESS.2018.2814081.

McWilliams, J. C., 2016: Submesoscale currents in the ocean. Proc. Roy. Soc. London, 472A, 20160117, https://doi.org/ 10.1098/rspa.2016.0117.

Nieto Borge, J. C., K. Reichert, and J. Dittmer, 1999: Use of nautical radar as a wave monitoring instrument. Coastal Eng., 37, 331-342, https://doi.org/10.1016/S0378-3839(99)00032-0.

—, G. Rodríquez Rodríguez, K. Hessner, and P. Izquierdo González, 2004: Inversion of marine radar images for surface wave analysis. J. Atmos. Oceanic Technol., 21, 1291-1300, https:// doi.org/10.1175/1520-0426(2004)021<1291:IOMRIF>2.0.CO;2.

Nikurashin, M., G. K. Vallis, and A. Adcroft, 2013: Routes to energy dissipation for geostrophic flows in the Southern Ocean. Nat. Geosci., 6, 48, https://doi.org/10.1038/ngeo1657.

Novelli, G., C. M. Guigand, C. Cousin, E. H. Ryan, N. J. Laxague, H. Dai, B. K. Haus, and T. M. Özgökmen, 2017: A biodegradable surface drifter for ocean sampling on a massive scale. J. Atmos. Oceanic Technol., 34, 2509-2532, https://doi.org/10.1175/ JTECH-D-17-0055.1.

Ohlmann, J. C., M. J. Molemaker, B. Baschek, B. Holt, G. Marmorino, and G. Smith, 2017: Drifter observations of submesoscale flow kinematics in the coastal ocean. Geophys. Res. Lett., 44, 330-337, https://doi.org/10.1002/2016GL071537.

Ortiz-Suslow, D. G., B. K. Haus, N. J. Williams, N. J. M. Laxague, A. J. H. M. Reniers, and H. C. Graber, 2015: The spatialtemporal variability of air-sea momentum fluxes observed at a tidal inlet. J. Geophys. Res. Oceans, 120, 660-676, https:// doi.org/10.1002/2014JC010412.

Plant, W. J., and W. C. Keller, 1990: Evidence of Bragg scattering in microwave Doppler spectra of sea return. J. Geophys. Res., 95, 16 299-16310, https://doi.org/10.1029/JC095iC09p16299.

_- and G. Farquharson, 2012: Wave shadowing and modulation of microwave backscatter from the ocean. J. Geophys. Res., 117, C08010, https://doi.org/10.1029/2012JC007912.

Poje, A. C., and Coauthors, 2014: Submesoscale dispersion in the vicinity of the Deepwater Horizon spill. Proc. Natl. Acad. Sci. USA, 111, 12 693-12 698, https://doi.org/10.1073/ pnas.1402452111.

Rascle, N., J. Molemaker, L. Mari, F. Nouguier, B. Chapron, B. Lund, and A. Mouche, 2017: Intense deformation field at oceanic front inferred from directional sea surface roughness observations. Geophys. Res. Lett., 44, 5599-5608, https:// doi.org/10.1002/2017GL073473.

Senet, C. M., J. Seemann, and F. Ziemer, 2001: The near-surface current velocity determined from image sequences of the sea surface. IEEE Trans. Geosci. Remote Sens., 39, 492-505, https://doi.org/10.1109/36.911108.

, — , S. Flampouris, and F. Ziemer, 2008: Determination of bathymetric and current maps by the method DiSC based on the analysis of nautical X-band radar image sequences of the sea surface (November 2007). IEEE Trans. Geosci. Remote Sens., 46, 2267-2279, https://doi.org/10.1109/ TGRS.2008.916474. 
Serafino, F., C. Lugni, and F. Soldovieri, 2010: A novel strategy for the surface current determination from marine X-band radar data. IEEE Geosci. Remote Sens. Lett., 7, 231-235, https:// doi.org/10.1109/LGRS.2009.2031878.

— , and Coauthors, 2012: REMOCEAN: A flexible X-band radar system for sea-state monitoring and surface current estimation. IEEE Geosci. Remote Sens. Lett., 9, 822-826, https:// doi.org/10.1109/LGRS.2011.2182031.

Shcherbina, A. Y., E. A. D’Asaro, C. M. Lee, J. M. Klymak, M. J. Molemaker, and J. C. McWilliams, 2013: Statistics of vertical vorticity, divergence, and strain in a developed submesoscale turbulence field. Geophys. Res. Lett., 40, 4706-4711, https:// doi.org/10.1002/grl.50919.

Shen, C., W. Huang, E. W. Gill, R. Carrasco, and J. Horstmann, 2015: An algorithm for surface current retrieval from X-band marine radar images. Remote Sens., 7, 7753-7767, https:// doi.org/10.3390/rs70607753.

Skolnik, M. I., 1981: Introduction to Radar Systems. McGraw-Hill, $581 \mathrm{pp}$.

Stewart, R. H., and J. W. Joy, 1974: HF radio measurements of surface currents. Deep-Sea Res. Oceanogr. Abstr., 21, 10391049, https://doi.org/10.1016/0011-7471(74)90066-7.

Streßer, M., R. Carrasco, and J. Horstmann, 2017: Video based estimation of surface currents using a low-cost quadcopter. IEEE Geosci. Remote Sens. Lett., 14, 2027-2031, https:// doi.org/10.1109/LGRS.2017.2749120.

Tamura, H., Y. Miyazawa, and L.-Y. Oey, 2012: The Stokes drift and wave induced-mass flux in the North Pacific. J. Geophys. Res., 117, C08021, https://doi.org/10.1029/2012JC008113.

Thomas, L. N., A. Tandon, and A. Mahadevan, 2008: Submesoscale processes and dynamics. Ocean Modeling in an
Eddying Regime, M. W. Hecht and H. Hasumi, Eds., International Geophysics Series, Vol. 177, Amer. Geophys. Union, 17-38, https://doi.org/10.1029/177GM04.

Trizna, D. B., 1997: A model for Brewster angle damping and multipath effects on the microwave radar sea echo at low grazing angles. IEEE Trans. Geosci. Remote Sens., 35, 1232 1244, https://doi.org/10.1109/36.628790.

Tuomi, L., O. Vähä-Piikkiö, P. Alenius, J.-V. Björkqvist, and K. K. Kahma, 2018: Surface Stokes drift in the Baltic Sea based on modelled wave spectra. Ocean Dyn., 68, 17-33, https://doi.org/ 10.1007/s10236-017-1115-7.

Valenzuela, G. R., 1978: Theories for the interaction of electromagnetic and oceanic waves - A review. Bound.-Layer Meteor., 13, 61-85, https://doi.org/10.1007/BF00913863.

Walker, N. D., W. J. Wiseman Jr., L. J. Rouse Jr., and A. Babin, 2005: Effects of river discharge, wind stress, and slope eddies on circulation and the satellite-observed structure of the Mississippi river plume. J. Coastal Res., 21, 1228-1244, https:// doi.org/10.2112/04-0347.1.

Weatherall, P., and Coauthors, 2015: A new digital bathymetric model of the world's oceans. Earth Space Sci., 2, 331-345, https://doi.org/10.1002/2015EA000107.

Wetzel, L. B., 1990: Electromagnetic scattering from the sea at low grazing angles. Surface Waves and Fluxes, G. L. Geernaert and W. L. Plant, Eds., Environmental Fluid Mechanics, Vol. 8, Springer, 109-171, https://doi.org/10.1007/978-94-009-0627-3_3.

Young, I. R., W. Rosenthal, and F. Ziemer, 1985: A threedimensional analysis of marine radar images for the determination of ocean wave directionality and surface currents. J. Geophys. Res., 90, 1049-1059, https://doi.org/10.1029/ JC090iC01p01049. 